\title{
Democratización, clases sociales e identidades políticas en la formación de la Argentina contemporánea
}

\section{Democratization, social classes and political identities in the making of the modern Argentina}

\author{
Sebastián Gimenez \\ Universidad Nacional de La Plata/Universidad Nacional de San Martin- \\ Instituto de Altos Estudios Sociales-CONICET, Argentina \\ sebasgim82@gmail.com
}

\section{Resumen:}

En el presente artículo nos proponemos analizar cómo las ciencias sociales -y principalmente los estudios que buscaron aunar las herramientas de la disciplina histórica con las de la sociología- abordaron el proceso de "democratización" en nuestro país. Para ello, prestamos particular atención a aquellos trabajos que se preguntaron por la manera en que la formación de las clases sociales en la Argentina de la primera mitad del siglo XX impactó sobre las formas de concebir las jerarquías y de construir el lazo social y político. Encontramos en estos trabajos hipótesis muy significativas y herramientas analíticas muy productivas para abordar la problemática referida. Pero también hallamos algunos déficits, principalmente en lo que hace a cómo se concibe la relación entre estado y sociedad. En las conclusiones, por lo tanto, esbozamos algunas líneas analíticas para seguir reflexionando sobre la cuestión con nuevos interrogantes y puntos de vista.

Palabras ClaVe: Democratización, Clases sociales, Argentina.

\section{Aвstract:}

The purpose of this article is to analyze how the social sciences -and mainly the studies that sought to bring together history and sociology- deal with the "democratization" process in our country. We pay special attention to those works that interrogate how the making of the social classes in Argentina during the first half of the XXth century had an impact on the way of conceiving the hierarchies and of constructing the social and political ties. We found in those studies very relevant hypothesis, and also very fruitful analytical skills to address the issue. But also we found some shortages, mainly in what refers to the way in which they conceive the relationship between state and society. Therefore, in the conclusions of this article, we outline some analytical lines in order to continue the reflections about this issue, with new interrogants and points of view.

KEYWORDS: Democratization, Social classes, Argentina.

\section{INTRODUCCIÓN}

La democratización es uno de los procesos característicos de la moderna sociedad occidental. Así, al menos, tendió a considerársela durante mucho tiempo. Quienes a fines del siglo XVIII fueron testigos de los acontecimientos que barrieron con el antiguo orden monárquico y feudal, destacaron el advenimiento de una era de igualdad como una de las grandes novedades que traería aparejado el nuevo mundo en formación, tan fascinante y temible en sus consecuencias como la secularización o la industrialización. El avance de la democracia, lejos de ser una mera ilusión de circunstancia fagocitada por el calor revolucionario, pronto se reveló como un fenómeno perdurable, merecedor de un análisis detenido. Fue Alexis de Tocqueville (1985 y 2004) quien con mayor sistematicidad se ocupó de desentrañar las características del proceso iniciado con la revolución de 1789. Él argumentó que en la democratización convivían dos dimensiones, la relativa al orden político, por un lado, y la referida a la vida social, por el otro. Si la primera de esas dimensiones aludía a la participación de un mayor número de personas en la esfera pública (la soberanía del pueblo), la segunda advertía sobre los cambios en la experiencia cotidiana sobrevenidos con el fin de la era de los 
privilegios: la representación de uno mismo y del otro se veía radicalmente transformada en una sociedad que había derribado las barreras estamentales que anteriormente dividían a los hombres entre sí. Como consecuencia de ello, argumentó Tocqueville, con la democracia era un nuevo "estado social" el que surgía, una nueva forma de lazo social entre los individuos. El advenimiento de la igualdad no podía concebirse, sin embargo, para el intelectual francés, como un acontecimiento que ocurría en un momento determinado. Era, antes bien, -y como lo señala uno de los más lúcidos analistas de su obra- "un movimiento perpetuo (perpetuum mobile) de las sociedades postaristocráticas" (Jaume, 2015, p. 41). Según Jaume, para Tocqueville "la democracia tendía a disminuir y suprimir todas las jerarquías -incluso revolviéndose ante las desigualdades intelectuales-" (Jaume, 2015, p. 138). En otras palabras, a lo que asistimos en el mundo moderno es sobre todo a un proceso de progresiva igualación, de creciente democratización. Para Tocqueville, dicho desarrollo de la igualdad constituía un destino inevitable de las sociedades modernas. La historia tenía para él, en efecto, un sentido: el de la progresiva igualación de las condiciones de vida entre los hombres.

Los cuatro elementos implicados en la reflexión de Tocqueville (democracia como forma de gobierno, como tipo social, como proceso, y como destino inevitable de las sociedades modernas) nos guiarán en la búsqueda que aquí pretendemos realizar sobre los modos en que fue pensado el proceso de democratización en el período de formación de la Argentina contemporánea. Nos interesa especialmente, en efecto, en el presente trabajo, analizar cómo se abordó desde las ciencias sociales -y principalmente desde aquellos estudios que buscaron aunar las herramientas de la disciplina histórica con las de la sociología- el proceso de democratización en nuestro país. Las preguntas que les formularemos a esos estudios serán las siguientes: ¿Qué se entiende por “democratización” en cada uno de los casos? ¿En qué marco temporal sitúan el proceso de democratización? ¿A quiénes se identifica como los agentes promotores de dicho proceso? ¿El locus de su impulso su ubica en la sociedad, en la política, en el estado, o en movimientos transversales a estas instancias? ¿Se trata de un proceso en "movimiento perpetuo", que puede saberse el momento de su principio pero no el de su final? ¿ $\mathrm{O}$ bien tiende a considerárselo como un fenómeno que tuvo límites temporales bien definidos?

Antes de adentrarnos de lleno en nuestro análisis, se impone realizar una aclaración y una digresión. La aclaración refiere al corpus al que vamos a dirigir este conjunto de interrogantes: aunque más adelante, al final de esta introducción, brindaremos más especificaciones al respecto, interesa señalar ahora que en este artículo analizaremos trabajos académicos que fueron producidos con posterioridad a la última dictadura militar. Creemos, en efecto, que en los años ochenta se modificó el paradigma con el que se pensó el proceso que aquí nos interesa abordar. La digresión, entonces, está referida a señalar el modo en que "tradicionalmente" (esto es: antes de 1983) se pensó la democratización. Al respecto, resulta de suma relevancia destacar que esta problemática ocupó un lugar de primer orden de importancia en la etapa fundacional de las ciencias sociales en nuestro país. En lo que hace a la historiografía, es sabido que los ensayos de Bartolomé Mitre (1950 y 1968) sobre las principales figuras de la independencia rioplatense estuvieron guiados por el objetivo de mostrar que la democracia era la forma social y política más apropiada para un país que había nacido en gran medida libre de las barreras estamentales que separaban a los hombres entre sí. La narrativa de Mitre -fuertemente influenciada por Tocqueville-, que postulaba que la democracia estaba inscripta en los orígenes de la nación y por lo tanto también en su futuro, impregnó a más de una generación de intelectuales y académicos, hasta bien entrado el siglo XX. En efecto, la visión que José Luis Romero articuló sobre la Argentina en los años 40 y los 50 puede leerse todavía en esa clave. ${ }^{1} Y$ la sociología "científica" que en esas mismas décadas hizo su aparición en el país tampoco estaría librada del todo de ella: en Gino Germani, la idea de una "democratización” en progresivo avance ocupa, de hecho, una centralidad insoslayable.

La obra de Germani puede considerarse, en este sentido, como el punto culmine de toda una manera de mirar la trayectoria del país. ${ }^{2}$ Germani (1962) utilizaba la expresión "democratización fundamental”, de Karl Mannheim, ${ }^{3}$ para dar cuenta del proceso por el cual los sectores medios primero y los populares después, se integraban a la sociedad urbano-industrial. Esto último es significativo: para el sociólogo italiano, la integración no se limitaba a tal o cual esfera de la vida social, sino a la sociedad moderna en su conjunto 
(lo cual implicaba la actividad gremial, la educación, "las aspiraciones", los consumos, y, desde luego, también la política). En todos estos órdenes se podía constatar una creciente igualación entre los diferentes sectores sociales. Los cuatro elementos que vimos en Tocqueville están por lo tanto también presentes en Germani: éste creía que la democratización era un proceso a la vez político y social, caracterizado por la tendencia a la igualación entre los diferentes sectores sociales, y destinado a imponerse de modo inevitable.

Posteriormente, sin embargo, no volverían a plantearse posturas como la de Germani. Distintas razones hicieron que una apuesta de esas características ya no fuera concebible: desde transformaciones teóricas que tornaron anacrónica la idea de mirar al pasado con la intención de descubrir en él la clave de lectura capaz de dar cuenta del destino entero de una comunidad -el tan mentado fin de los "grandes relatos" y de las perspectivas teleológicas-, hasta la propia experiencia argentina, que a fuerza de sucesivas crisis y desgarramientos internos se ocupó de desmentir cualquier pretensión de mostrar que la igualdad constituía el norte seguro para su sinuoso rumbo.

Esto no quiere decir que la democratización dejara de estar presente en las ciencias sociales de nuestro país del período posterior a la última dictadura militar, que es el que aquí nos interesa indagar. Ciertamente, la idea de que la igualdad constituye un hecho providencial, y que por ello está destinada a ganar creciente territorio hasta reinar soberana y sin cuestionamientos, debió ser abandonada. Pero, despojada de ese componente teleológico, investigadores de distintas disciplinas siguieron acudiendo a ese término para dar cuenta de algunos procesos que tuvieron lugar en la Argentina de la primera mitad del siglo XX. Dos maneras de hacer uso del concepto pueden rápidamente identificarse: en primer lugar, desde perspectivas pertenecientes o cercanas a la ciencia política, se recurrió a él para dar cuenta del proceso de ampliación del demos comunitario. Es éste, creemos, un modo "débil" de pensar la democratización, que llega a confundirse, en algunos casos, con la enumeración de normativas y disposiciones institucionales: así, por ejemplo, es usual pensar en la Ley Sáenz Peña como una primera instancia de ampliación de la esfera ciudadana, a la que le siguió luego el derecho al voto femenino y finalmente la provincialización de los territorios nacionales. ${ }^{4}$

En el presente artículo nos interesa detenernos en el análisis del segundo modo de hacer uso del concepto, el cual no se limitó a la sola esfera institucional, sino que -acercándose más a la inspiración tocquevilleanaabordó sobre todo el vínculo entre sociedad y política. Nos centraremos entonces en aquellos trabajos que problematizaron cómo ciertos procesos impactaron en las formas de concebir las jerarquías sociales, y, ligado a ello, cómo se operaron cambios en las formas construir el lazo social y político.

Enfocado el tema desde este punto de vista, hay una línea de investigación que sobresale por la relevancia que otorgó a la problemática. Nos referimos a aquella que abordó el proceso de formación de las clases sociales en nuestro país: tanto los estudios sobre la conformación de la clase obrera y los sectores populares, como aquellos referidos a las clases altas y a las elites, colocaron en un primer orden de importancia a la cuestión de las jerarquías vigentes en la sociedad argentina en la primera mitad del siglo XX, al tiempo que fueron particularmente sensibles para captar los procesos de impugnación y desafío hacia ellas. Esto es, desde luego, fácilmente comprensible, dado que hablar de clases sociales y estratificación implica necesariamente interrogarse por las jerarquías que sostienen y "ordenan" la estructura social.

Esta primera delimitación del "objeto" de nuestro estudio sigue siendo, empero, todavía demasiado abarcativa. Como sabemos, son muy numerosos los trabajos que se propusieron analizar diversos aspectos de los sectores sociales que dieron forma a la sociedad argentina. Sin embargo, bien mirados, rápidamente surge la evidencia de que la mayoría de ellos se limita a dilucidar tal o cual dimensión específica del fenómeno bajo análisis. Son pocos los trabajos que insertan esa reflexión en el marco de una reconstrucción amplia y sistemática sobre la evolución de la sociedad argentina en su conjunto.

Estos últimos trabajos son precisamente los que tienen relevancia para el objetivo que aquí perseguimos, en tanto nos interesa detenernos, no en los modos en que se configuró un actor en particular, sino en la manera en que el surgimiento de dicho actor impactó sobre la dinámica política y social en su conjunto. Así definido nuestro objeto, las aproximaciones a tener en cuenta surgen con mayor nitidez: en el caso de los sectores 
obreros y populares, es la intervención de Juan Carlos Torre la que sobresale; y, en el de las elites, las de Roy Hora y Leandro Losada. En las páginas que siguen, analizaremos, pues, cómo, en cada caso, fue abordada la cuestión de la democratización, atendiendo a las preguntas que formulamos con anterioridad.

\section{DeMOCRATIZACión y SECTORES POPULARES}

Aunque Juan Carlos Torre no haya escrito un libro en el que condensara su mirada sobre el proceso de formación de la clase obrera argentina en la primera mitad del siglo XX, las líneas centrales de su interpretación pueden reconstruirse con nitidez a partir de los diferentes ensayos que desde fines de los años ochenta publicó sobre el tema. En particular, resultan de particular interés los trabajos en que supo combinar una preocupación historiográfica de largo aliento con una fuerte vocación teórica. Entre ellos, sobresale su clásico artículo sobre los orígenes del peronismo (1989), y su más reciente intervención en la que reflexiona sobre los motivos por los cuales no existió en nuestro país un "fuerte movimiento obrero socialista" (2009). En ambos trabajos, Torre presenta la misma línea analítica para explicar las formas que adquirió el proceso de formación de una clase trabajadora articulada a nivel nacional. Y en ambos, el concepto de democratización ocupa un lugar de primer orden de importancia.

Torre considera que en el trascurso de las décadas del diez y del veinte nuestro país asistió a un proceso de democratización. Desde su punto de vista, con la Ley Sáenz Peña la elite dirigente intentó desactivar el potencial disruptivo de los movimientos de protesta surgidos hacia fines del siglo anterior. Quienes diseñaron la apertura política se habían propuesto integrar a una parte de la oposición para ensanchar las bases de legitimidad del régimen. Sin embargo, Torre -siguiendo aquí los argumentos ya esgrimidos por Natalio Botana (1977)- considera que de ningún modo figuraba en los planes de los reformistas la posibilidad de que el radicalismo se alzara con el triunfo en la elección presidencial de 1916. Ellos contaban con que un buen desempeño electoral en algunos distritos le habilitara al partido liderado por Yrigoyen -así como a otras fuerzas opositoras- el acceso a la representación minoritaria. El fracaso de este derrotero es lo que conduce a Torre a hablar del "colapso de la operación transformista diseñada por la elite dirigente". De tal modo, la victoria de la UCR en 1916, según el autor, "ubicó a la Argentina en un casillero aparte en los procesos de democratización vía reforma, cuyo rasgo común es asegurar a quienes promueven el cambio el control de la apertura del sistema político" (2009, p. 43).

La democratización que se operó en la segunda década del siglo XX es definida entonces por Torre como una que tuvo lugar "vía reforma". El autor no avanza en mayores precisiones acerca de las razones por las cuales decidió llamar de este modo a la experiencia que analiza. Una posibilidad es que con dicha categoría aludiera al hecho de que la democratización que entonces tuvo lugar no fue vía revolución. ${ }^{5}$ Pero esta expresión no aparece en el texto ni, en rigor, tampoco en ninguna otra parte de su obra. Si nos atenemos a los términos presentes en ésta, emerge con nitidez el origen del concepto: en sus trabajos sobre el período de surgimiento del peronismo, Torre (1989) recupera la terminología de Alain Touraine para contraponer los procesos de cambio político "propios de una sociedad reformista", de aquellos que son motorizados por el estado y que tienen un carácter "autoritario" (más adelante nos explayaremos sobre esta problemática yuxtaposición). El clivaje para él significativo es entonces el que divide estado y sociedad. En consecuencia, lo que Torre pareciera querer subrayar con la idea de una democratización "via reforma”, es que la sociedad jugó un rol muy activo en el proceso que condujo a ella. En su trabajo sobre los orígenes del peronismo éste es el aspecto que el autor, de hecho, destaca: allí contrasta el proceso de cambio político de los años 40, que según su visión fue comandado por el estado, con el de principios de siglo, en el cual existió una movilización social -de los sectores mediosque encontró un canal de expresión política autónomo -el partido radical-y que logró presionar al bloque de poder para obtener el resultado que buscaba -la reforma electoral-. Si bien la resolución se operó a través del estado, existió, previamente, un prolongado período de movilización, que aseguró al movimiento un fuerte arraigo en la sociedad civil. 
Es este primer elemento el que enfatiza Torre con su conceptualización de "democratización via reforma". Pero hay algo más que merece ser subrayado, que tiene que ver no tanto con el sendero "reformista" sino con el tipo de democratización que entonces se puso en marcha. ¿Qué carácter tuvo ésta? ¿A qué sectores alcanzó e involucró en su desarrollo? Ya dijimos que, para Torre, la elite y los sectores medios estuvieron implicados en el inicio del proceso de ampliación de la ciudadanía política. Pero éste no se agotó en ellos. Sucede que el partido que accedió al gobierno supo potenciar a gran escala los efectos contenidos en dicha ampliación. De tal modo, si bien el radicalismo, cuando hizo su aparición en la vida pública en el año 90, expresó una disidencia al interior de la elite, y si bien luego, al consolidarse como la oposición más intransigente hacia el régimen oligárquico, reclutó su principal base de apoyo en los sectores medios, una vez que accedió al gobierno en 1916 mostró una gran versatilidad para ampliar todavía más su capacidad de convocatoria, hasta llegar a alcanzar con su prédica (y con sus políticas) a los sectores obreros y populares. Éstos fueron, por lo tanto, incluidos en el sistema político. Mostrando receptividad hacia las demandas de los gremios obreros, y distribuyendo a través de su densa red de comités recursos del estado hacia los sectores populares, los gobiernos radicales supieron integrar efectivamente a los trabajadores en el esquema de funcionamiento de la democracia ampliada.

Es aquí donde Torre cree posible ver los efectos de la democratización política, los cuales, en su interpretación, no se limitaron al terreno electoral. Dicho de otro modo: el alcance de la democratización no se agotó en la incorporación de nuevos sectores sociales a la vida política. Ésta ciertamente se transformó por el hecho de ver acrecido el número de ciudadanos integrados a su esfera de influencia. Pero, al mismo tiempo, la política también surtió sus efectos sobre el terreno social, el cual experimentó un giro al encontrarse con un estado dispuesto a entrometerse activa y directamente en el conflicto que lo estructura: el que contrapone a los propietarios con los no propietarios de los medios de producción.

En gran medida, todo esto explica para Torre que el radicalismo capitalizara una porción importante del voto obrero. A tal punto tuvo éxito la UCR en su llamado a los trabajadores que, según su punto de vista, fue sobre todo su sólida presencia la que impidió el desarrollo de un fuerte movimiento obrero socialista en la Argentina. Según el autor, tal como sucedió en los Estados Unidos, "también aquí la capacidad de un partido policlasista en el poder de absorber las demandas obreras redujo el espacio disponible para que fructificara y echara raíces la convocatoria de una oferta socialista" (2009, p. 48).

Ahora bien, si por un lado Torre subraya los avances experimentados por la UCR en su apelación a los trabajadores, al mismo tiempo demarca muy precisamente los límites de sus logros. Sucede que los mismos obreros que periódicamente expresaban en las urnas su apoyo al partido radical, en el terreno propio de la acción gremial seguían prestando su adhesión a ideologías y movimientos clasistas. Existió en Argentina, en efecto, -y esta es la clave interpretativa más relevante que le interesa introducir al autor-, una "cisura entre las luchas obreras y las luchas cívicas" (2009, p. 41), o bien -como lo señala en otro texto en el que hace referencia a esta misma cuestión- una "falta de correspondencia entre condición obrera e identificación política de clase” (2012, p. 14). La raíz de esta disociación se encuentra, para Torre, en el temprano proceso de democratización política que aquí tuvo lugar. En sus palabras: "debido al acceso de los trabajadores al sistema político, no hubo una clara superposición de los antagonismos en ambos campos de la acción obrera. De allí que la movilización política y los enfrentamientos entre trabajadores y capitalistas fuesen dos ejes con frecuencia independientes" (Torre, 2012, p. 19).

Las condiciones para que se produjera una yuxtaposición entre las dos dimensiones (política y social) de la acción obrera recién se dieron a partir de la década del treinta. Esto se debió a que allí, en el período de la restauración conservadora, "el sistema político dejó de funcionar como vehículo de la presión de sectores del mundo del trabajo (...) En estas condiciones, que eran las de un bloque económico dominante y políticamente excluyente en el control del estado, las prácticas de los trabajadores comenzaron a ganar mayor consistencia interna" (Torre, 2012, p. 19). Es decir, para Torre, la década del treinta representó un fenomenal retroceso en el proceso de democratización que el país había experimentado a principios de siglo: por un lado, los trabajadores fueron excluidos de la esfera política; por el otro, el gobierno pasó a estar bajo el control directo 
del sector empresario. En los 30 la burguesía coincidió así con la elite dirigente en el estado. Los trabajadores enfrentaron entonces un adversario homogéneo en el terreno económico y en el político. Los conflictos se tornaron "transparentes", habilitando, en potencia, el espacio para el surgimiento de un movimiento obrero "autónomo" -esto es: libre de la influencia de fuerzas "pluriclasistas", y con la capacidad de actuar por cuenta propia no sólo en la esfera económica, sino también en la política-.

Subrayamos recién que durante el período de la restauración conservadora sólo en potencia se abrió el espacio para el surgimiento de un movimiento obrero "autónomo". Si en las primeras décadas del siglo XX lo que obstaculizó su desarrollo fue la presencia del radicalismo, en los 30 Torre señala la existencia de trabas institucionales que bloquearon la organización sindical. La modernización económica que tuvo lugar en los años posteriores a la gran crisis de 1930 se tradujo, afirma, en "la integración estructural y el ascenso objetivo del mundo del trabajo" (1989, p. 529). Pero si las condiciones “objetivas" para el desarrollo de la autonomía obrera estaban dadas, faltaban las políticas e institucionales. ${ }^{6}$ En este contexto, sólo una intervención del estado podía "debilitar las interdicciones sociales y desbloquear el sistema político para, de un mismo golpe, abrir las puertas a la participación de los sectores populares” (1989, p. 533).

Fue precisamente eso lo que hizo Perón desde la Secretaría de Trabajo y Previsión Social: utilizó las herramientas que el poder del estado ponía en sus manos para derribar la autocracia patronal, hacer posible la organización sindical de los trabajadores, y promover, simultáneamente, su integración en el sistema político. Por todo ello, con el peronismo asistimos a un proceso de ampliación de derechos (Torre habla de "acceso a la ciudadanía industrial"), el cual, aunque tiene su locus en la esfera productiva, de ningún modo se limita a ella: comprende, antes bien, una experiencia global, que modifica el lugar de los trabajadores en la sociedad, y por lo tanto implica un trastocamiento de las jerarquías hasta entonces vigentes. En palabras de Torre:

Por los derechos que reconoce, por la influencia que otorga a quienes han estado hasta entonces excluidos, el proyecto del estado trasciende el terreno de la producción para acelerar la crisis de la deferencia que la vieja sociedad jerárquica acostumbraba a esperar de sus estratos más bajos. De esta manera, la gestión de la elite militar vuelve efectivo lo que existía en forma virtual en el origen, en las condiciones iniciales del proceso de cambio político por efecto de la modernización: nos referimos a la descomposición de un modelo hegemónico global y al desencadenamiento de un estado de movilización social generalizado (1989, p. 534).

Crisis de la deferencia, resquebrajamiento de la vieja sociedad jerárquica, descomposición de un modelo hegemónico global: Torre nos conduce de lleno al problema de la democratización. Y es de hecho este concepto el que el autor introduce inmediatamente a continuación. Retomando la categorización de Alain Touraine, Torre afirma que el peronismo fue un proceso de "democratización por via autoritaria”. ¿Por qué decide calificar de este modo el ensayo de apertura llevado a cabo por el gobierno militar? ¿Qué rasgos hacen del peronismo en formación una experiencia democratizadora pero "autoritaria"? Dice Torre en el crucial pasaje en que hace referencia a esta cuestión:

Los derechos adquiridos por los trabajadores después de 1943 no son el resultado de prolongadas luchas contra un poder de clase adverso entronizado en el estado. Más bien, estamos ante un proceso de democratización por via autoritaria, utilizando la definición de Alain Touraine, en el cual el cambio político no sigue la secuencia que va desde las luchas sociales a las reformas institucionales, sino que es motorizado por la acción de ruptura de la elite estatal. Es, pues, en el contexto de una iniciativa lanzada desde arriba como se activa en la sociedad una movilización que combina la lucha de clases y la participación, el enfrentamiento con los patrones pero también con las estructuras que protegen sus privilegios. Así las cosas, la fusión de las dos vertientes de la movilización dentro de un movimiento político no llega a ser asegurada por los agentes directos de clase -los sindicatos y partidos obreros-, sino por la nueva elite dirigente, cuya acción de ruptura del orden dominante comanda el cambio político (1989, pp. 534-535).

Si nos atenemos a estas palabras, encontramos dos motivos diferentes por los cuales Torre considera "autoritario" el proceso de ampliación de derechos iniciado en 1943: primero, porque fue motorizado desde el estado sin que la intervención de éste estuviera precedida por una fuerte movilización social; segundo, 
porque la fusión de las dos dimensiones (de nuevo: política y social) de la acción obrera fue "asegurada" por una elite externa a la clase trabajadora, imposibilitando el desarrollo de la autonomía sindical.

Puestos en estos términos, ambos elementos resultan sumamente problemáticos. En lo que hace al primero de ellos, si seguimos hasta las últimas consecuencias el razonamiento que lo sostiene, terminaríamos considerando "autoritaria" toda iniciativa emanada del estado que no respondiera a una previa conflictividad social. De tal modo, para no ser autoritaria, una medida de gobierno debería esperar a que una demanda se desarrolle hasta cuajar en un movimiento social que se alce en lucha frente a él mismo. Lo cual resulta, lógicamente, un absurdo. El segundo argumento es cuestionable porque, dado que el autor no avanza en mayores precisiones, parece quedar sostenido en una pura base valorativa. Esto se refuerza si tenemos en cuenta las categorías utilizadas por Torre, las cuales tienen un notorio componente no sólo normativo, sino también político. En efecto, ¿por qué calificar de "heterónoma" la participación obrera en una experiencia de cambio político comandada por el estado? ¿Por qué sería "autoritaria" la intervención de un agente externo que asegure la fusión de las dos dimensiones de la acción obrera? Las respuestas a estos interrogantes quizá se puedan encontrar en el momento en que fue elaborada la perspectiva de Torre: nos referimos a los años ochenta del siglo pasado, cuando, en reacción frente a la experiencia trágica del terrorismo de estado, se consolidó, en el ámbito político y también en el académico, una mirada que tendió a valorar como positivas aquellas experiencias que resguardaban la autonomía de lo social frente a la política. La instancia social fue entonces concebida como un espacio que debía conservar su independencia, en tanto constituía el principal reaseguro ante las potenciales tendencias autoritarias que siempre emanan del estado. En definitiva, es esta visión política y normativa la que Torre proyecta hacia el pasado. Subyace a ella un modelo ideal de movilización contestataria, que considera que ésta debe constituirse plenamente en el terreno económico social, permaneciendo reticente a los llamados realizados por otras fuerzas políticas, principalmente si éstas tienen vínculos con el estado.

Resulta significativo, a este respecto, que Torre parece haber advertido el carácter parcial y problemático de su conceptualización. En la última edición que publicó de su clásico artículo (Siglo XXI, 2012) decidió, en efecto, desechar la categoría "democratización por vía autoritaria”, y aludir, en su reemplazo, a la noción de "democratización por vía estatal". El reemplazo de la palabra "autoritaria” por "estatal” es el único cambio que el autor introdujo en el texto. Todo lo demás permanece igual (incluso la referencia a Touraine como fuente inspiradora del concepto). No es posible encontrar ninguna explicación ni aclaración acerca de por qué decidió realizar tan importante modificación. Más allá de cuáles hayan sido sus intenciones, lo cierto es que, si bien el nuevo concepto tiene la ventaja de morigerar la fuerte carga valorativa presente en el anterior, no soluciona, creemos, los límites que recién identificamos.

Teniendo en cuenta estos señalamientos, es que disentimos con Omar Acha y Nicolás Quiroga (2012), quienes consideran que Torre lleva a cabo una operación de "normalización" del primer peronismo. ${ }^{8}$ Por lo contrario, nosotros creemos que en él sigue presente una fuerte patologización de la experiencia peronista. Ciertamente, ésta no opera del mismo modo que en Germani, quien, en última instancia, atribuía lo patológico del peronismo a un rasgo de la conciencia obrera. Torre, como es de sobra conocido, toma distancia en este punto del sociólogo italiano, y, apoyándose en los argumentos esgrimidos por Murmis y Portantiero (1971), afirma la racionalidad que guió la conducta de los trabajadores en su acercamiento hacia Perón. Pero, en nuestra opinión, desplazado del nivel "agencial”, el aspecto patológico es reintroducido por Torre en un nivel "estructural”. Es decir: ya no es un actor en particular el que es considerado patológico, sino el modo en que se opera la integración de ese actor en la comunidad. Este proceso de integración es patológico porque no es societal (reformista), sino estatal (autoritario).

Existe, efectivamente, como afirman Acha y Quiroga, una idea “evolucionista” en la visión que Torre ofrece de la historia argentina, en el sentido de que, para él, primero tuvo lugar una democratización política (acceso a la ciudadanía política) y luego una democratización social (acceso a la ciudadanía industrial). Pero derivar de aquí una operación de "normalización" -como hacen estos autores- resulta, a nuestro criterio, 
apresurado, puesto que el modo en que se operó la segunda democratización conllevó, para Torre, una desviación de un sendero original (afín al modelo "ideal") que hacía que los cambios políticos se procesaran desde abajo hacia arriba, y no a la inversa. Lo que se perdió, entonces, en el tránsito de la primera a la segunda democratización, fue el carácter activo y protagónico de "la sociedad". Con ello, quedó clausurada la "vía reformista", y sólo permaneció habilitada la "vía autoritaria". De tal modo, si es cierto que existe un rasgo "evolucionista" en la visión que erige Torre de la historia argentina, también lo es que él convive con una fuerte impronta "decadentista", la cual deriva de pensar en una original sociedad dinámica (la de fines del siglo XIX y principios del XX), que luego extravió sus energías al punto de que todas ellas fueron reabsorbidas por el estado, resultando éste, finalmente (a mediados de siglo), el único motor posible del cambio político.

Una consecuencia clave se desprende de esto, que es central para nuestro argumento: aunque Torre insinúe un modo amplio y multifacético de pensar la democratización (allí cuando habla de crisis de la deferencia y de descomposición de un modelo hegemónico global), finalmente ella termina siendo abordada sólo en términos de acceso a derechos (y, quizá, de mera concesión de derechos). ${ }^{9}$ De aquí que puedan convivir, en un mismo concepto (el de democratización por vía autoritaria), dos categorías que a priori resultarían difíciles de pensar en conjunto, tales como democratización y autoritarismo. Hay dos fuerzas en tensión en estos conceptos: el primero de ellos conlleva el reforzamiento de vínculos horizontales, la puesta en cuestión de las jerarquías, y el establecimiento de una comunidad más igualitaria; el segundo subraya la verticalidad, la jerarquización y la diferencia. Torre parece no advertir el carácter paradójico de hacer converger ambos términos. Al no mediar una reflexión teórica al respecto, los dos términos pueden coexistir sólo a condición de que uno prime sobre el otro. Y en Torre, es el autoritarismo el que se impone a la democratización. Ésta queda confinada a una acción (acceso a derechos) y a un momento muy particular de la experiencia peronista (la de sus orígenes). El autoritarismo, en contrapartida, cubre todo lo que la democratización no abarca.

Esta crucial cuestión -sugerida pero no explorada sistemáticamente por Torre- de la compleja relación entre experiencias populistas, autoritarismo, y procesos de democratización ha sido recientemente abordada por autores que se propusieron analizar detenidamente los legados de las experiencias nacional-populares en nuestro país. Particularmente relevantes al respecto resultan los trabajos de Gerardo Aboy Carlés (2007 y 2005), quien advierte sobre la necesidad de distinguir entre dos conceptos afines pero no iguales: democracia y democratización. Los populismos, según este autor, son movimientos "claramente homogeneizadores en lo que refiere a la expansión de nuevos derechos (...) Es esta fuerza homogeneizadora e inclusiva del populismo, esta dimensión jacobina, la que hace del mismo una fuerza democratizadora" (2005: 137). De tal modo, si los populismos ponen en acto movimientos de democratización de la comunidad, es porque llevan adelante procesos de homogeneización; esto es: de igualación comunitaria. De aquí que, para Aboy Carlés, "el populismo constituye la principal tradición democrática en la historia argentina. Una tradición por cierto reñida con el liberalismo político y que ha sido uno de los principales obstáculos a la hora de intentar establecer una institucionalidad pluralista" (2005: 138). En la eterna tensión entre igualdad y libertad (teorizada por Tocqueville), los populismos se inclinan claramente hacia el polo de la igualdad, en desmedro de la libertad. Es este el motivo por el cual, si ellos son democratizadores, en contrapartida suelen someter a la democracia (y, particularmente, a la democracia liberal) a fuertes tensiones. De aquí deriva, entonces, en última instancia, ese rasgo suyo que algunos autores, como Torre, caracterizan como "autoritario".

Se entiende así que el balance de la experiencia peronista (y, seguido de ello, de la democratización) que se desprende del análisis de Torre resulte tan problemático. Efectivamente, el autor señala como aspecto positivo el mayor acceso a derechos que conllevó dicha experiencia. Pero esto se logró al precio de reforzar la primacía del estado, subordinar al sindicalismo y ahogar las fuerzas de la sociedad. La democratización trajo consigo, en definitiva, una ampliación de la distancia entre estado y sociedad. Retengamos este aspecto que, de un modo distinto, también reaparecerá en quienes han visto el proceso de democratización "desde arriba", es decir, analizando a las clases altas y a las elites. 


\section{Democratización y ELITES}

A principios de este nuevo siglo surgieron algunos trabajos de historia social que tomaron a las elites como objeto privilegiado de análisis. Los autores que en este campo sobresalen son Roy Hora y Leandro Losada. Si bien, en un primer momento, cada uno de ellos focalizó su atención en aspectos diferentes y específicos del fenómeno, ${ }^{10}$ luego avanzaron en trabajos (algunos realizados en conjunto, como: Hora y Losada, (2011) en los que se propusieron reconstruir de modo más integral el devenir de la elite en la sociedad argentina.

La cuestión de la democratización está muy presente en todos estos estudios. Un primer elemento significativo que surge de ellos es que esta problemática es remitida a un período anterior al que usualmente se admite. Así, por ejemplo, el proceso independentista de principios del siglo XIX es identificado como un episodio de ruptura de las jerarquías vigentes durante la colonia. Roy Hora, en este sentido, afirma: "Las invasiones inglesas de 1806 y 1807 y las prolongadas guerras de independencia movilizaron y politizaron a la población, debilitaron el orden político y social, y dieron impulso a acusados procesos de democratización" (2002, p. 16). Algunas características económico-sociales del escenario rioplatense potenciaron luego este rasgo igualitario y plebeyo. En particular, su carácter de sociedad de frontera impuso límites a los sectores dominantes. En palabras de Hora: "Rasgo típico de las sociedades nuevas, la pampa carecía de las relaciones deferenciales que caracterizaban a sociedades rurales más antiguas y jerárquicas" (2002, p. 25).

Los autores sitúan los enormes cambios suscitados en la estructura social a partir de 1880, en consecuencia, no sólo en el marco del fenomenal crecimiento que experimentó la economía argentina en el último tercio del siglo XIX, sino también sobre aquel trasfondo de más largo plazo, que nos remite a la existencia de una sociedad todavía abierta y móvil, la cual, con la llegada de la inmigración masiva, no hizo sino acentuar esos rasgos. En efecto, quienes a fines del novecientos arribaron a las costas del Río de La Plata se encontraron con un país que, pese a los cíclicos vaivenes de su economía, en términos generales demandaba más brazos de los disponibles, lo cual permitía negociar en mejores condiciones el salario y apropiarse así de una porción relativamente significativa de la riqueza generada por la economía en expansión. Ello dio lugar al temprano surgimiento de vastos sectores medios, tanto en las ciudades como en las campañas del Litoral.

Precisamente el hecho de que los sectores trabajadores experimentasen una mejora sustancial en sus condiciones de vida -y teniendo en cuenta además la debilidad de las jerarquías hasta entonces existentesplanteó a la elite el desafío de erigir barreras de distinción. Hora y Losada muestran cuántos esfuerzos (y recursos) invirtieron los sectores económicamente más poderosos para lograr diferenciarse. En opinión de Losada, "en la Argentina, la europeización en clave aristocrática respondió a la búsqueda de las elites tradicionales (...) de resguardarse de las incipientes capas medias surgidas al compás de la modernización capitalista" (2009,p.184).

¿Logró la elite su cometido de ser reconocida como el sector socialmente preponderante? Los autores no tienen dudas al respecto, y el término belle époque que ellos utilizan quiere precisamente dar a entender que fue allí, en el entresiglos, cuando aquélla vivió su etapa de esplendor. En palabras de Losada, "es el período en que la alta sociedad adquiere su mayor relevancia como el centro de todas las miradas, como el grupo de referencia en lo tocante a modales, gustos y aficiones para quienes aspiraban a construir un status prestigioso" (2008, XXVIII).

Cuatro interrogantes se desprenden de lo dicho hasta aquí: ¿̨uáles fueron las bases sobre las cuales se erigió la sólida posición de la elite en la cumbre de la sociedad? ¿Quiénes eran los que "aspiraban” a construir un estatus prestigioso, procurando imitar a la elite? ¿Hasta cuándo gozó ésta del amplio prestigio que supo ganarse en las décadas del cambio de siglo? ¿En qué medida la democratización tuvo que ver con esto? Detengámonos un momento en cada uno de estos aspectos.

En lo referido al primero de los interrogantes, Hora y Losada están de acuerdo en que el pilar sobre el cual se edificó la posición de preeminencia de la elite fue su enorme capacidad de acumulación de riqueza, 
posibilitada por la concentración de la propiedad de la tierra. Pero, además, tal como señala Roy Hora, "la augusta posición de los terratenientes dependía del dinamismo de la sociedad rural, y en particular de su capacidad para generar amplias oportunidades de ascenso económico y social” (2002, p. 208). Es decir, la burguesía terrateniente presidía sobre un orden social que, si la tenía a ella como principal beneficiaria, al mismo tiempo se revelaba capaz de incluir a importantes sectores sociales en un movimiento de ascenso colectivo generalizado. Esto contribuía a erosionar potenciales conflictos, y a dotar de consenso tanto al régimen económico y social vigente, como a quienes más esfuerzos habían hecho por implantarlo.

En este contexto, logró cuajar la imagen que los estancieros construyeron de sí mismos, como empresarios modernizadores y progresistas. Lo cual nos conduce a la segunda cuestión mencionada. $\mathrm{Al}$ respecto, Hora y Losada, al subrayar la amplia legitimidad de que gozaron los hombres y mujeres más encumbrados, sugieren que fue el conjunto de la sociedad el que los reconoció como merecedores de la posición distinguida en que ellos se colocaron a sí mismos. Pero los autores señalan específicamente un sector que se referenció en la elite y que moldeó prácticas y valores siguiendo, ante todo, su ejemplo. Hablamos de los incipientes sectores medios que, al calor del crecimiento económico, estaban definiendo una identidad propia. Según afirman los autores, "hasta los años del Centenario, el ascendiente de la elite sobre los sectores medios en proceso de expansión constituye la fuerza predominante que da forma a este vínculo" (Hora y Losada, 2011, p. 628).

Si éste es, entonces, el panorama predominante, se impone la pregunta acerca de cuándo y a raíz de qué procesos se produjo el eclipse de la elite. En este aspecto, los autores no dudan en identificar a los años que siguieron al Centenario como un parteaguas. Lo relevante aquí es que Hora y Losada señalan que los procesos que erosionaron la sólida posición de la elite en la cumbre de la sociedad fueron múltiples, y siguieron temporalidades diversas. El surgimiento del conflicto social en la pampa fue un primer elemento que contribuyó a socavar el prestigio de la elite: habíamos dicho que el consenso que ésta detentó fue posible porque el modelo económico que la tenía por principal beneficiaria integraba también a sectores más amplios en un movimiento de ascenso colectivo. Fue esto lo que, luego de 1910, comenzó a encontrar sus límites. Con el cierre de la frontera agrícola, la pampa perdió muchas de las características que la habían hecho una sociedad nueva: la rápida valorización de la tierra contribuyó a dotar de un perfil de clases más preciso a la sociedad rural, tornando más difícil la movilidad social. Este proceso es el que explica el surgimiento de la conflictividad en el ámbito rural, que tuvo en el Grito de Alcorta su cristalización más emblemática. Los terratenientes fueron señalados a partir de allí como los representantes de una clase parasitaria e improductiva. La imagen de empresarios progresistas y modernizantes que aquéllos habían detentado comenzó así a horadarse.

Lo que complicó más las cosas fue que ello tuvo lugar en el preciso momento en que la Argentina avanzaba en la democratización política. Si la elite en general acompañó al presidente Sáenz Peña en su vocación por sanear las prácticas políticas, Hora afirma que fueron los terratenientes quienes se mostraron particularmente optimistas al respecto. Esto se explica porque los dueños de la tierra "percibían que su posición social estaba mejor enraizada en la sociedad que en el orden político, y que por tanto era independiente de la suerte de los grupos gobernantes oligárquicos" (2002, p. 232). Pero estas expectativas no sobrevivieron a la prueba de la realidad: "Lo que sorprendió (y luego amargó) a las clases altas y a los políticos del viejo orden fue la emergencia (...) de prácticas políticas nuevas, mucho más plebeyas y populistas de lo que esos grupos estaban preparados para aceptar" (Hora, 2002, p. 234). Páginas más adelante, concluye el autor: "Al dejar voz a una sociedad que se había vuelto políticamente más compleja y socialmente menos armoniosa, la democratización debilitó la posición de las clases propietarias" (2002, p. 256). ${ }^{11}$

Hasta aquí tenemos entonces un proceso económico (cierre de la frontera agrícola) y otro político (instauración del sufragio popular) que contribuyeron a erosionar el lugar privilegiado de la elite. A ellos hay que agregarles otros dos, de índole social el uno, y cultural el otro. El que remite a lo social tiene que ver con la especialización de campos sociales, motorizada por cambios estructurales que recorrieron a la sociedad y que contribuyeron a distanciar a unos sectores de otros; afirman los autores: 


\begin{abstract}
"A la vez que el influjo de la alta sociedad sobre las clases medias se atenuaba, ambos conjuntos pasaron a conceder mayor importancia a su propio entorno al momento de perfilar valores e identidades. Este proceso se encuentra ligado a la creciente complejidad de la sociedad, que sin duda contribuyó a volver más heterogéneas las referencias sociales y culturales en torno a las cuales se articulaba la identidad de cada grupo (algo que, por ejemplo, Alexis de Tocqueville ya había advertido en los Estados Unidos de mediados del siglo XIX). Conforme la sociedad se tornaba más compleja, el influjo social de la elite, sin desaparecer del todo, habría perdido intensidad, y habría comenzado a ser opacado por un universo de valores y referencias más propiamente mesocrático" (Hora y Losada, 2011, p. 625).
\end{abstract}

Los "valores mesocráticos" que mencionan los autores son aquellos vinculados al esfuerzo, el ahorro, el trabajo y la honestidad. Fue alrededor de estos valores burgueses y no aristocráticos que los sectores medios forjaron una identidad propia, quizá no opuesta, pero sí diferente a la de la elite. ${ }^{12}$ Este proceso comenzó a desplegarse después del Centenario, y tomó una forma nítida en el período de entreguerras; en estos años, en efecto, "el universo de las clases medias alcanzó la fuerza y la solidez suficientes como para morigerar el influjo que sobre él ejercía la elite (...) relegando a la alta sociedad a un papel no sólo reactivo sino también cada vez más marginal en la vida argentina” (Hora y Losada, 2011, p. 628).

Finalmente, los autores señalan la irrupción de la cultura de masas como un proceso que coadyuvó al desplazamiento de la alta sociedad del centro del escenario social. Según Hora y Losada, luego de la Primera Guerra Mundial, se "abrió una era de creciente democratización de la vida social y cultural” (2011, p. 626). De tal modo, "aficiones y consumos de signo aristocratizante (...) cedieron ante el avance de otros que, como el jazz o el tango, no tenían sus matrices en la alta cultura” (Hora y Losada, 2011, p. 626). Y concluyen: "El sentido en el que circulaban estas novedades era de abajo hacia arriba más que de arriba hacia abajo, por lo que estos procesos sirvieron, más que para reforzar el ascendiente cultural de la elite, para erosionarlo y acotarlo" (Hora y Losada, 2011, p. 626).

En conjunto, entonces, lo que nos muestran Hora y Losada es que, en el período de entreguerras, la combinatoria de múltiples procesos redundó en la progresiva declinación de la alta sociedad tradicional. En gran medida, los autores tienden a ver la democratización como el correlato de dicha declinación. Pero aquí hay un punto sobre el que conviene llamar la atención: la democratización, aunque siempre mencionada, no aparece pensada en sí misma, sino remitida como el trasfondo que, en gran medida, actúa como contraparte del eclipse de la elite. Surge aquí, entonces, un interrogante que para nosotros es clave (y sobre el que nos explayaremos en las conclusiones): ¿debe pensarse que la pérdida de importancia de la alta sociedad tradicional implicó necesariamente un proceso de democratización? ¿O bien para que podamos hablar de un proceso de estas características es necesario atender a otras dimensiones?

\title{
4. Conclusiones
}

Como se puede apreciar, Hora y Losada proveen una clave de lectura imprescindible para entender diferentes aspectos de la Argentina de entreguerras: de manera convincente, nos muestran cómo fue visto "desde arriba" ese país que dejaba atrás el orden oligárquico y elitista. Lejos de encontrarnos con una alta sociedad segura de sí misma y con capacidad para moldear los destinos de la comunidad, hallamos, luego del Centenario, a un grupo social desafiado y en retirada, que, en paralelo a su declinación económica, vio también cercenado su ascendiente político, social y cultural sobre el conjunto de la sociedad. Esa marginación de la elite es asimilada por los autores a un proceso de "democratización".

¿Alcanza con dar cuenta de una decadencia de los sectores dominantes tradicionales para afirmar que se está en presencia de una democratización? ¿O haría falta además reconocer otros aspectos? Si esto es así, ¿cuáles serían esas dimensiones? A este respecto, creemos que Juan Carlos Torre apunta en una dirección muy relevante al hablar de crisis de la deferencia y de descomposición de un modelo hegemónico global. Pero su mirada debe ser repensada tanto histórica como conceptualmente. En primer lugar, en cuanto a lo histórico, su visión debe ser ajustada en función de las diferentes temporalidades de declinación de la elite 
que esbozan Hora y Losada, y que llevaría a ritmar los avances y retrocesos de la democratización no sólo en función del proceso político, sino atendiendo también a otras variables (económicas, sociales y culturales). Si en general esta mirada conllevaría una nueva forma de abordar las primeras décadas del siglo XX, creemos que podría tener un impacto particularmente acentuado en el modo de considerar los años 30: ¿hasta qué punto puede afirmarse que allí tuvo lugar una simple reversión de la democratización, tal como sostiene Torre? ¿No se desplegaron entonces paralelamente otros procesos que, iniciados después del Centenario, siguieron actuando en sus efectos durante esos años? Si esto es así, ¿en qué medida llevaría eso a repensar el proceso de ampliación de derechos que tuvo lugar durante el peronismo? Y en particular, ¿hasta qué punto puede considerarse que todo lo que a partir de 1943 tuvo lugar fue a causa del Estado? En segundo lugar, en cuanto a lo conceptual, se impone, como ha señalado Barros (2011) una elaboración más compleja de lo que implica la crisis de la deferencia, la descomposición de un modelo hegemónico, y el replanteamiento de los límites comunitarios.

Finalmente, existe, tanto en los trabajos de Torre como en los de Hora y Losada, otro aspecto sobre el cual creemos necesario profundizar la reflexión: nos referimos a la espinosa cuestión de la relación entre estado y sociedad. En el caso de Torre, ya vimos cómo el Estado tiende a ser considerado como la fuente generadora de autoritarismo, y, por lo tanto, los procesos de democratización que aspiran a ser efectivamente tales, deben, según su visión, emanar directamente de la sociedad. Hora y Losada no articulan una mirada similar. Pero resulta sumamente llamativo que los procesos que ellos identifican como impulsores de la democratización en la Argentina remitan siempre a la sociedad civil: esto es evidente en el caso de los procesos económicos, sociales y culturales (que analizamos más arriba); pero incluso aquellos propiamente políticos son puestos por los autores por fuera de la instancia estatal. Así, lo que se señala como democratizador del radicalismo es su liderazgo "populista", categoría ésta que se entiende de modo exclusivamente descriptivo (es decir, como sinónimo de "plebeyo"). Creemos que es precisamente este aspecto el que debe repensarse, para lo cual un uso analítico de la categoría de populismo podría ser de mucha ayuda. En efecto, quienes más sistemáticamente han reflexionado sobre este tipo de fenómenos (Laclau, 2005; Aboy Carlés, 2005, 2007 y 2013; Melo, 2009 y 2012) han advertido sobre el carácter fuertemente democratizador que ellos han cumplido. Los populismos aspiraron a la creación de un espacio político homogéneo, para lo cual el despliegue de diferentes políticas estatales (desde la intromisión en el conflicto social hasta las intervenciones federales) fue un factor clave. A la hora de continuar pensando sobre la democratización en la Argentina de la primera mitad del siglo XX, sobre sus diferentes temporalidades, y sobre las formas en que ella afectó al lazo social y político, creemos necesario, por lo tanto, incorporar esta perspectiva. La inspiración de Tocqueville puede ser nuevamente de ayuda a este respecto: como es largamente sabido, la mayor homogeneización social constituía para el intelectual francés la otra cara de la mayor centralización estatal (tanto es esto así, que, según su visión, si la Revolución Francesa pudo instaurar el principio igualitario de la soberanía popular, fue porque previamente la monarquía absoluta había concentrado el grueso de poder en el estado). He allí una clave de lectura para seguir interrogando los fenómenos de democratización y el papel que en ellos hubieron de jugar los movimientos nacional-populares.

\section{BIBLIOGRAFIA}

Aboy Carlés, G. (2005). Populismo y democracia en la Argentina contemporánea. Entre el hegemonismo y la refundación. Estudios Sociales, 28.

Aboy Carlés, G. (2007). La democratización beligerante del populismo. Debate, 9.

Aboy Carles, G. (2013). El radicalismo yrigoyenista y el proceso de nacionalización del espacio político. Una interpretación a través de los usos del concepto de hegemonía. Identidades, 4.

Adamovsky, E. (2009). Historia de la clase media argentina. Apogeo y decadencia de una ilusión. Buenos Aires: Planeta. Acha, O. y Quiroga, N. (2012). El hecho maldito. Conversaciones para otra historia del peronismo. Rosario: Prohistoria ediciones. 
Barros, S. (2011). La crisis de la deferencia y el estudio de las identidades políticas en los orígenes del peronismo. Papeles de trabajo, 8 .

Blanco, A. (2009). Karl Mannheim en la formación de la sociología moderna en América Latina. Estudios sociológicos, XXVII (80).

Botana, N. (1977). El orden conservador. La politica argentina entre 1880 y 1916. Buenos Aires: Sudamericana.

De Tocqueville, A. (1985). La democracia en América. Madrid: Alianza (dos tomos).

De Tocqueville, A. (2004). El Antiguo Régimen y la Revolución. Madrid: Alianza.

Germani, G. (1962). Politica y sociedad en una época de transición. Buenos Aires: Paidós.

Halperín Donghi, T. (1980). José Luis Romero y su lugar en la historiografía argentina. Desarrollo económico, 20 (78).

Hora, R. (2002). Los terratenientes de la pampa argentina. Una historia social y politica, 1860-1945. Buenos Aires: Siglo XXI.

Hora, R. (2009). Los estancieros contra el Estado. La Liga Agraria y la formación del ruralismo politico en Argentina. Buenos Aires: Siglo XXI.

Hora, R. (2014). Historia del turf argentino. Buenos Aires: Siglo XXI.

Hora, R. (2015). Una familia de la elite argentina. Los Senillosa, 1810-1930. Buenos Aires: Prometeo.

Hora, R. y Losada L. (2011). Clases altas y medias en la Argentina, 1880-1930. Notas para una agenda de investigación. Desarrollo económico, 50 (200).

Jaume, L. (2015). Tocqueville: los origenes aristocráticos de la libertad. Una biografía intelectual. Madrid: Tecnos.

Laclau, E. (2005). La razón populista. Buenos Aires: FCE.

Losada, L. (2008). La alta sociedad de la Buenos Aires de la Belle Époque. Sociabilidad, estilos de vida e identidades. Buenos Aires: Siglo XXI.

Losada, L. (2009). Historia de las elites en la Argentina. Desde la Conquista hasta el surgimiento del peronismo. Buenos Aires: Sudamericana.

Melo, J. (2009). El efecto populista. Territorios nacionales, provincializaciones y lógica populista durante el primer peronismo. Pilquen, 16.

Melo, J. (2012). La democracia populista. Populismo y democracia en el primer peronismo. Pensamiento Plural, 2 (3).

Mitre, B. (1950). Historia de San Martín y de la emancipación sudamericana. Buenos Aires: El Ateneo.

Mitre, B. (1968). Historia de Belgrano. Buenos Aires: Eudeba.

Murmis, M. y Portantiero, J. C. (1971). Estudios sobre los orígenes del peronismo. Buenos Aires: Siglo XXI.

O'donnell, G. (1997). Contrapuntos. Ensayos escogidos sobre autoritarismo y democratización. Buenos Aires: Paidós.

Torre, J. C. (1989). Interpretando (una vez más) los orígenes del peronismo. Desarrollo económico, 28 (112).

Torre, J. C. y Pastoriza, E. (2002). "La democratización del bienestar". En J. C. Torre (dir.), Los años peronistas (1943-1955). Buenos Aires: Sudamericana.

Torre, J. C. (2009). ¿Por qué no existió un fuerte movimiento socialista en Argentina?. En C. Hilb (Comp.), Elpolitico y el cientifico. Ensayos en homenaje a Juan Carlos Portantiero (pp. 33-50). Buenos Aires: Siglo XXI.

Torre, J. C. (2012). Introducción. En J. C. Torre, Ensayos sobre movimiento obrero y peronismo (pp. 13-36). Buenos Aires: Siglo XXI.

\section{Notas}

1 Como bien señala Tulio Halperín Donghi, "Romero no entra en la historia argentina para buscar (...) un sentido que la historiografía existente no es capaz de proponer persuasivamente: su esfuerzo lo ubica en una línea interpretativa previa, cuya dirección general lo satisface plenamente. Así, Las ideas políticas en Argentina razona y continúa la interpretación del pasado nacional propuesta por los clásicos de la historiografía argentina, y sobre todo por Mitre” (1980, p. 264)

2 Desde luego, no hay pura continuidad entre las perspectivas de Mitre o Romero y la del intelectual italiano. Éste, fuertemente deudor de la teoría de la modernización, no podía dejar de leer los cambios acontecidos en la Argentina bajo 
el prisma de un marco conceptual que otorgaba prioridad epistemológica al proceso por el cual una sociedad tradicional devenía en una moderna. Dado que un fuerte quiebre se producía en el pasaje del viejo al nuevo orden, los rasgos del nuevo tipo de sociedad no podían estar todos contenidos en el anterior estadio. La democracia, entonces, para Germani -y a diferencia de Mitre-, no estaba presente desde un principio en la comunidad nacional. Ella sobrevenía como una consecuencia (inevitable) del proceso de modernización.

3 Sobre la relación entre Germani y Mannheim, véase: Blanco (2009).

4 Un derivado último de esta forma de entender el concepto fue el que se hizo para dar cuenta del proceso de recuperación de los derechos civiles y políticos luego de las experiencias dictatoriales de los años setenta y ochenta: "democratización" se utilizó entonces como sinónimo de "transición del autoritarismo a la democracia”. Los trabajos de Guillermo O’donnell (1997) fueron, en este sentido, paradigmáticos.

5 Recordemos que, en el contexto político en que la Ley Sáenz Peña fue concebida, el camino revolucionario se encontraba dentro del horizonte de posibilidades, en tanto el radicalismo había ensayado la alternativa armada de modo persistente desde 1890 en adelante.

6 Sostiene Torre: "Si la industrialización va definiendo a los protagonistas del conflicto social, éste no llega a articularse: para que el terreno de la producción sea el lugar de un conflicto abierto de clases es preciso que se levanten las barreras e interdicciones que reproducen la autocracia patronal. Lo que nos remite en este caso a la limitada institucionalización de las relaciones del trabajo" (1989, p. 530).

7 Ciertamente, los autores construyen su argumento tomando como referencia otro trabajo de Torre, escrito en colaboración con Elista Pastoriza (2002). Las líneas analíticas de este texto, sin embargo, no difieren de aquellas que Torre había elaborado en sus trabajos sobre los orígenes del peronismo, y que luego volvería a recuperar en otros posteriores.

8 Los autores entienden por "normalización" a la operación política-epistémica por la cual las ciencias sociales de nuestro país empezaron a presentar al peronismo como un fenómeno no disruptivo de la historia nacional. Si los primeros estudios sobre el tema habían subrayado su carácter anormal, y, por lo tanto, rupturista, posteriormente, las explicaciones de los científicos sociales buscaron inscribir al fenómeno en el marco de sus antecedentes históricos, planteando que, lejos de ser algo extraordinario, el peronismo encontraba sus raíces en tendencias de más largo plazo de nuestro devenir histórico. La despatologización, de tal modo, para Acha y Quiroga, forma parte de una cosmovisión "evolucionista y progresista" que tiene como uno de sus ejes limar las afirmaciones inmoderadas de corte radical con la historia.

9 En su aguda crítica al texto de Torre sobre los orígenes del peronismo, Sebastián Barros (2011) ha insistido especialmente en este punto.

10 Mientras Hora analizó sobre todo el proceso de formación económica y política de la burguesía agraria pampeana (2002), Losada centró su atención en los aspectos sociales y culturales que dieron forma a la alta sociedad porteña de la belle époque (2008).

11 En el mismo sentido, Losada señala: "la reforma electoral rompió con la lógica elitista que había primado en la política argentina hasta su sanción. El imperio del sufragio universal, secreto y obligatorio, por la ampliación de las bases de sustentación y de legitimidad políticas que supuso, implicó que las demandas de las mayorías no pudieran ser sistemáticamente desoídas. Esto generó una brecha entre las elites políticas y las elites económicas” (2009, p. 223).

12 Los autores toman así distancia de la hipótesis sostenida por Ezequiel Adamovsky (2009), quien había enfatizado la dimensión política de la identidad de unos sectores medios que, por otra parte, recién se habrían conformado como grupo a mediados de siglo. 